\title{
Microwave-activated structured reactors to maximize propylene selectivity in the oxidative dehydrogenation of propane
}

\author{
Adrian Ramirez ${ }^{[\mathrm{a}, \mathrm{d}]}$, Jose L. Hueso ${ }^{[\mathrm{a}, \mathrm{b}, \mathrm{c}]^{*}}$, Reyes Mallada ${ }^{[\mathrm{a}, \mathrm{b}, \mathrm{c}]}$ and Jesus Santamaria ${ }^{[\mathrm{a}, \mathrm{b}, \mathrm{c}]^{*}}$ \\ ${ }^{a}$ Institute of Nanoscience of Aragon and Department of Chemical and Environmental Engineering, University of \\ Zaragoza. C/Mariano Esquillor s/n, 50018 Zaragoza (Spain). \\ ${ }^{b}$ Networking Research Center on Bioengineering, Biomaterials and Nanomedicine (CIBER-BBN), 28029, Madrid \\ (Spain). \\ ${ }^{c}$ Instituto de Ciencia de Materiales de Aragon (ICMA), Consejo Superior de Investigaciones Científicas (CSIC- \\ Universidad de Zaragoza) \\ ${ }^{d}$ Present Address: King Abdullah University of Science and Technology (KAUST), 23955, Thuwal \\ (Saudi Arabia).
}

\begin{abstract}
Microwave (MW) heating has been applied to increase the selectivity to propylene in the oxidative dehydrogenation $(\mathrm{ODH})$ of propane. The preferential heating of the solid monolith (made of $\mathrm{SiC}$, a good microwave susceptor), allows working with a lower gas phase temperature, reducing the formation of undesired by-products in the gas phase via homogeneous reactions. Conversion levels of $\sim 21 \%$ and selectivity to propylene up to $70 \%$ have been achieved with MW-heated straight channel monolithic reactors coated with a $\mathrm{VMgO}$ catalyst. These competitive values contrast with the more limited performance delivered by the same catalytic system when it is subjected to conventional heating in a fixed-bed reactor configuration, thereby corroborating the advantage of working under a significant gas-solid temperature gap to minimize the extent of homogeneous reactions.
\end{abstract}

Keywords: microwave chemistry $\bullet$ propylene production $\bullet$ silicon carbide $\bullet$ oxidative dehydrogenation

- structured reactors 


\section{Introduction}

The catalytic oxidative dehydrogenation $(\mathrm{ODH})$ of alkanes to alkenes offers an interesting alternative to the conventional synthesis of alkenes in the chemical industry by direct dehydrogenation $[1,2]$. Among all the oxidative dehydrogenations, the ODH of propane is one of the most relevant due to the huge importance of its main product, propylene, the second most produced chemical intermediate in the petrochemical industry after ethylene [3]. Traditionally, the main reaction pathway for propylene production is based on naphta cracking [4]. Nevertheless, over the course of the years, this process has been unable to successfully fulfill the increasing worldwide production demand and additional reaction routes have been proposed to overcome the propylene production gap [3]. In this regard, a large fraction of the propylene produced worldwide is presently obtained through the catalytic direct dehydrogenation of propane [5].

The main disadvantage of the current direct dehydrogenation route is that the reaction is strongly endothermic [6]. In addition, coke formation rapidly deactivates the catalyst at the high temperatures required. The alternative oxidative route [7] using molecular oxygen to give propylene and water has not been implemented yet because of the limited selectivity levels. These low selectivities are a direct consequence of the competing series-parallel pathway that leads to the formation of deep oxidation products $\left(\mathrm{CO}, \mathrm{CO}_{2}\right)$ as well as the co-generation of lighter hydrocarbons such as methane and/or ethylene in the homogeneous gas phase $[8,9]$. In this regard, it would be desirable to find novel catalysts capable of increasing propylene yields by: (i) minimizing the effects of over-oxidation [10] and/or (ii) working at reaction temperatures sufficiently low as to prevent homogeneous competing gas phase.

The conventional catalysts for the $\mathrm{ODH}$ of propane [11-13] are mostly based on vanadium (VMgO [14-16], $\mathrm{V} / \mathrm{Al}_{2} \mathrm{O}_{3}$ [17-19], $\mathrm{V} / \mathrm{SiO}_{2}$ [20-22], etc.), working usually at the highest temperature possible, since for a given conversion the selectivity increases with temperature [23-25]. However, increasing the temperature also leads to the concomitant formation of other gas-phase by-products such as ethylene and methane $[1,9,26]$, thereby hindering considerably the propylene selectivity. Therefore, these 
homogeneous gas phase contributions effectively set an upper limit in the propylene yield: as the temperature is raised progressively above $550^{\circ} \mathrm{C}$, a strong decrease of propylene selectivity takes place mainly due to its thermal cracking into methane and ethylene [2, 27].

Two well-differentiated competing reaction pathways can take place in the propane oxidative process [26]: i) the heterogeneous route in the surface of the catalyst following a Mars-Van Krevelen mechanism with $\mathrm{CO}$ and $\mathrm{CO}_{2}$ as undesired byproducts, and, ii) the homogeneous route in the gas phase that preferentially forms methane and ethylene (see Scheme 1). So far, most of the efforts to improve propylene selectivity have been devoted to the development of smarter catalyst formulations $[8,10]$. However, gas phase reactions are inherent to the gas phase chemistry of the process and independent of the catalyst nature. For this reason, the limitation associated to reaction temperature cannot be circumvented. Within this topic, some alternatives typically addressed to reduce the gas phase role have been already explored. In 1990 Kung et al. designed a specific reactor that reduced the homogeneous contributions by packing most of the gas phase volume with quartz chips, which not only acted as a radical quencher but also reduced free volume at the expense of increasing bed pressure [23]. 

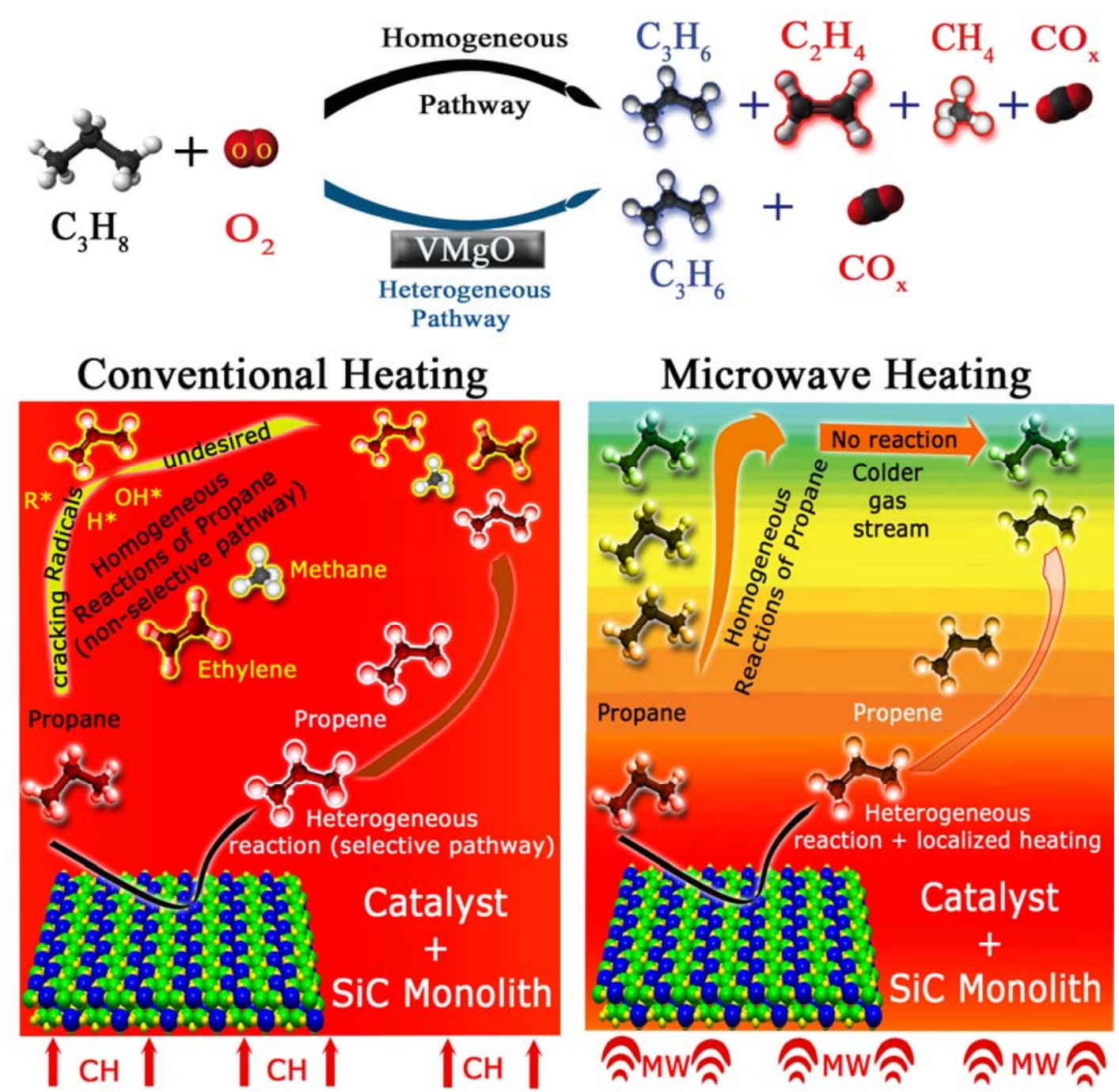

Scheme 1. Proposed ODH propane reaction pathways that can take place depending on the operating temperature and the heating mechanism (conventional versus microwave-assisted). MWH facilitates a temperature gap between the $\mathrm{SiC}$ monolith where the $\mathrm{VMgO}$ catalyst is deployed and the gas phase. The preferential heating enables a different temperature in the gas phase and prevent undesired non-selective secondary reactions typically occurring at higher temperatures under conventional heating conditions (i.e. with homogeneous high reaction temperatures).

Another approach to mitigate this contribution was proposed by Sadykov et al. through the use of monolithic supports based on Pt with low contact times [28]. Cooling the reactor outlet was proposed by Pavlova et al. with the same goal of minimizing the homogeneous formation of ethane and methane [29]. Nevertheless, none of these approaches was completely successful and nowadays the vast majority of the experiments never exceeds $500{ }^{\circ} \mathrm{C}$ as temperature threshold $[8,24]$ to minimize the gas phase reactions. 
In this work, we have explored the use of microwave (MW) irradiation as a tool that enables working with lower gas phase temperatures. In our previous works we have shown that direct heating of the solid (support + catalyst) under MW irradiation (the gas heating is negligible in the MW field) in monolith reactors allows to work under a stable solid-gas temperature gradient [30]. Thus, the gas phase temperature can be significantly lower (approx. 50K) than onto the solid support, helping to avoid undesired gas phase reactions. This concept has been previously demonstrated in the oxidative dehydrogenation of isobutane using $\mathrm{CO}_{2}$ (rather than oxygen) as the oxidant [31]. In that system, the catalyst was almost $100 \%$ selective and all unselective contributions came from the gas phase. In this work, we have applied the same concept to oxidative dehydrogenation of propane with oxygen as the oxidant, a more complex system, where both the catalyst and the gas phase are able to deliver selective and non-selective contributions. To demonstrate the wide applicability of the concept we have chosen $\mathrm{VMgO}$, a well known oxidative dehydrogenation catalyst with no significant MW absorption properties attributable to the $\mathrm{MgO}$ support [32]. Selective MW heating was instead obtained by deploying the catalyst on an excellent MW susceptor, SiC structured support. Therefore, the direct microwave heating of the solid phase can be applied to any catalyst, irrespective of its MW absorption properties.

\section{Experimental Section}

\subsection{Chemicals}

Magnesium Hydroxide $\left(\mathrm{Mg}(\mathrm{OH})_{2}\right.$ 99\%, Aldrich), Ammonium Metavanadate $\left(\mathrm{NH}_{4} \mathrm{VO}_{3} 99 \%\right.$, Aldrich) and Ammonium Hydroxide solution $\left(\mathrm{NH}_{4} \mathrm{OH}\right.$, Aldrich) were all used as received. Silicon carbide monoliths with straight, $1.5 \mathrm{~mm}$ channels were purchased from IRESA INGENIERIA S.L. and Silicon carbide foams with 30 ppi porosity were purchased from SICAT CATALYSTS INC.

\subsection{Characterization techniques}

Scanning electron microscopy (SEM) analysis was carried out with a FEI-Inspect S50 equipment. X-ray diffraction patterns were obtained in a PANalytical Empyrean equipment in Bragg Brentano configuration using $\mathrm{CuK}$ radiation and equipped with a PIXcellD detector. Raman spectra were 
recorded on an Alpha 300 Raman spectrometer of WITec. Excitation of the samples was carried out with a $633 \mathrm{~nm}$ Helium-Neon laser at room temperature. TEM (Transmission electron microscopy) images were acquired with a FEI Tecnai T20 operated at $200 \mathrm{kV}$ and a FEI Tecnai F30 at $300 \mathrm{kV}$ at the LMA (Laboratorio de Microscopias Avanzadas). Aberration corrected scanning transmission electron microscopy images were acquired using a high angle annular dark field detector in a FEI XFEG TITAN electron microscope operated at $300 \mathrm{kV}$ equipped with a CETCOR Cs-probe corrector from CEOS Company allowing forming an electron probe of $0.08 \mathrm{~nm}$. The geometric aberrations of the probeforming system were controlled to allow a beam convergence of $24.7 \mathrm{mrad}$ half-angle to be selected. Elemental analysis was carried out with EDS (EDAX) detector which allows performing EDX experiments in scanning mode. The samples were suspended in doubly-distilled water, under sonication, and 3 drops of each sample were carefully dropcasted onto $\mathrm{Cu}$ mesh grids.

\subsection{Catalyst preparation and deposition}

The preparation of the $\mathrm{VMgO}$ catalyst was done according the work of Kung et al. [33, 34]. The preparation of catalyst-coated reactors was done according to our recent work [31]. Briefly, the catalyst deposition was carried out by controlled immersion of the structured supports in ethanolic suspensions of catalyst particles $(0.5 \mathrm{~g}$ of catalyst in $30 \mathrm{~mL})$ inside an ultrasonic bath for 15 minutes followed by calcination for $2 \mathrm{~h}$ at $250^{\circ} \mathrm{C}$. This cycle of immersion-sonication and heating was repeated several times until the desired catalyst loading was achieved (ca. $50 \mathrm{mg}$ of total loading corresponding to $\sim 5 \%$ loading). Both SiC supports had less than $20 \mathrm{~m}^{2} / \mathrm{g}$ of surface area. The syntheses of the nanomaterials have been performed by the Platform of Production of Biomaterials and Nanoparticles of the NANOBIOSIS ICTS, more specifically by the Nanoparticle Synthesis Unit of the CIBER in BioEngineering, Biomaterials \& Nanomedicine (CIBER-BBN).

\subsection{Microwave heating system and temperature measurements}

Microwave-induced heating was addressed in a TE510 monomodal cavity equipped with a magnetron generator operating at $2.45 \mathrm{GHz}$ (maximum power $300 \mathrm{~W}$ ). The experimental set-up is described elsewhere $[30,31]$ and a detailed scheme can be found in the SI. The structured reactor $(15 \mathrm{x}$ 
$15 \mathrm{~mm}$ ) was placed inside a quartz tube with internal diameter $16 \mathrm{~mm}$, introduced in the microwave cavity, at a nodal position where the electric field reaches a maximum. The gas inlet $(100 \mathrm{mLSTP} / \mathrm{min}$; 10\% Propane, $5 \%$ Oxygen, $85 \%$ Helium) was introduced from the bottom part of the quartz tube. The monolith/foam temperature was increased from 500 to $600{ }^{\circ} \mathrm{C}$ in steps of $25^{\circ} \mathrm{C}$, varying the microwave power from 50 to $75 \mathrm{~W}$. The flow rate was set to obtain a space velocity WHSV equals to $2 \mathrm{~L} \mathrm{~min}^{-1} \mathrm{gcat}^{-}$ 1. The reactor was pretreated under the reaction atmosphere at $550{ }^{\circ} \mathrm{C}$ for 2 hours. The composition of the outlet gas was analysed by online gas chromatography (Agilent 490 Micro GC) equipped with thermal conductivity detectors and two gas separation columns (a PPQ and a MS5A molecular sieve) using $\mathrm{He}$ as carrier. $\mathrm{CO}, \mathrm{CH}_{4}$ and $\mathrm{O}_{2}$ were analysed on the $\mathrm{MS} 5 \mathrm{~A}$ while $\mathrm{CO}_{2}$ and the $\mathrm{C}_{2}-\mathrm{C}_{3}$ hydrocarbons were analysed on the PPQ. Hydrogen formation was not monitored during the experiment. Closure of carbon balance was better than $2 \%$.

During reaction, the temperature of the catalyst top surface was measured with a pyrometer located in the upper part of the tube and an external thermographic camera that had a direct view of the quartz tube. The external thermographic camera was used as a control measurement to verify (indirectly) that no significant hot-spots were formed during reaction. The thermographic camera is a NEC InfRec R300 which operates over 8-14 $\mu \mathrm{m}$ and allows temperature measurement between $-40{ }^{\circ} \mathrm{C}$ and $500{ }^{\circ} \mathrm{C}$ with a sensitivity (NETD) of $0.03 \mathrm{~K}$, a spatial resolution of $1.2 \mathrm{mrad}$ and an accuracy of $\pm 1.0 \mathrm{~K}$. The pyrometer is an OPTRIS CL 2MH1 with a temperature range 490 to $2000{ }^{\circ} \mathrm{C}$, a spectral range of $1.6 \mu \mathrm{m}$, a sensitivity (NETD) of $0.1 \mathrm{~K}$ and an accuracy of $\pm 1.0 \mathrm{~K}$. The temperatures were continuously recorded using commercial software, after calibrating the emissivity of the surface as a function of temperature $[30,35]$. For preliminary experiments to compare temperature differences between solid and gas depending on the heating mode, an optical fiber (Neoptix Fiber Optic sensor, temperature range from -270 to $+300{ }^{\circ} \mathrm{C}$, response time of 500 milliseconds, accuracy of $\pm 0.8 \mathrm{~K}$ ) was placed at $1 \mathrm{~mm}$ downstream of the solid monolith/foam to measure the temperature of the exit gas, while the solid temperature was measured by the pyrometer facing the gas exit side of the monolith/foam. However, 
these measurements were limited to a maximum of $300{ }^{\circ} \mathrm{C}$, due to the temperature limitations of the optical fiber.

For conventional heating, the same quartz tube was placed inside an electrical oven. In this case temperature profiles were measured with the pyrometer and a thermocouple located in the central position of the structured reactor, connected to a PID controlled electrical furnace to maintain the desired temperature.

\section{Results and Discussion}

\subsection{Preparation of the structured catalysts and evaluation of their heating capabilities under microwave irradiation}

$\mathrm{VMgO}$ was selected as ODH propane catalyst and synthesized according to the work by Kung et al. $[33,34]$ (see also Experimental Section for further details). XRD analysis confirmed the presence of two crystalline structures corresponding to magnesium oxide $(\mathrm{MgO})$ and magnesium orthovanadate $\left(\mathrm{Mg}_{3}\left(\mathrm{VO}_{4}\right)_{2}\right)$, respectively (Figure 1b). This latter structure consists of chains of edge-sharing $\mathrm{MgO}_{6}$ units linked together by isolated $\mathrm{VO}_{4}$ tetrahedra [33]. HAADF-STEM analysis coupled with EDXmapping analysis detected a fairly homogeneous distribution of the elements, $\mathrm{V}, \mathrm{Mg}$ and $\mathrm{O}$ in the catalysts nanoparticles (Figure 1a).

A closer EDX evaluation of different areas revealed different $\mathrm{V} / \mathrm{Mg}$ ratios between an isolated nanoparticle placed in an outer area (Figure 1c referred to Area 1) and a larger area including several nanoparticles (see Figure 1c referred to Area 2). High-Resolution TEM images further corroborated the co-existence of both crystalline species, being $\mathrm{MgO}$ preferentially present as an external layer (Figure $\mathrm{S} 1)$. Raman spectroscopy confirmed the presence of the $\left(\mathrm{Mg}_{3}\left(\mathrm{VO}_{4}\right)_{2}\right)$ plus a small contribution of nanostructured vanadium oxides at $258 \mathrm{~cm}^{-1}$ (Figure S2). The SEM-EDX analysis also shows an average composition containing ca $37 \%$ wt. $\mathrm{Mg}$ and $28 \%$ wt. V (Figure S3).

Since the VMgO catalyst does not exhibit a good capability to absorb microwaves, it was deployed onto the surface of silicon carbide $(\mathrm{SiC})$ structured reactors. The dielectric properties of SiC make this 
material an excellent candidate for MW induced heating [36]. In addition, SiC remains remarkable inert under reaction conditions (i.e. temperatures above $450{ }^{\circ} \mathrm{C}$ and an oxidative atmosphere). Two different $\mathrm{SiC}$ commercial monoliths were evaluated as structured supports: $\alpha$-SiC monoliths with straight, $1 \mathrm{~mm}$ channels, and $\beta$-SiC foams with 30 ppi porosity (see Figure 1d and 1e). Both supports had less than 20 $\mathrm{m}^{2} \mathrm{~g}^{-1}$ according to $\mathrm{N}_{2}$ isotherm absorption measurements. The diameter and total length was $12 \mathrm{~mm}$ for both supports. X-Ray Diffraction and Raman spectroscopy measurements confirmed the presence of the $\mathrm{SiC}$ phases (either in the hexagonal or cubic phase) (see Figures S4 and S5). One of the most critical challenges when applying microwave heating to heterogeneous catalysis consists on achieving a nearly homogeneous heating of the solid to prevent the formation of hot spots, which usually lowers product selectivity or generates misleading and difficult to interpret catalytic results $[35,37]$.
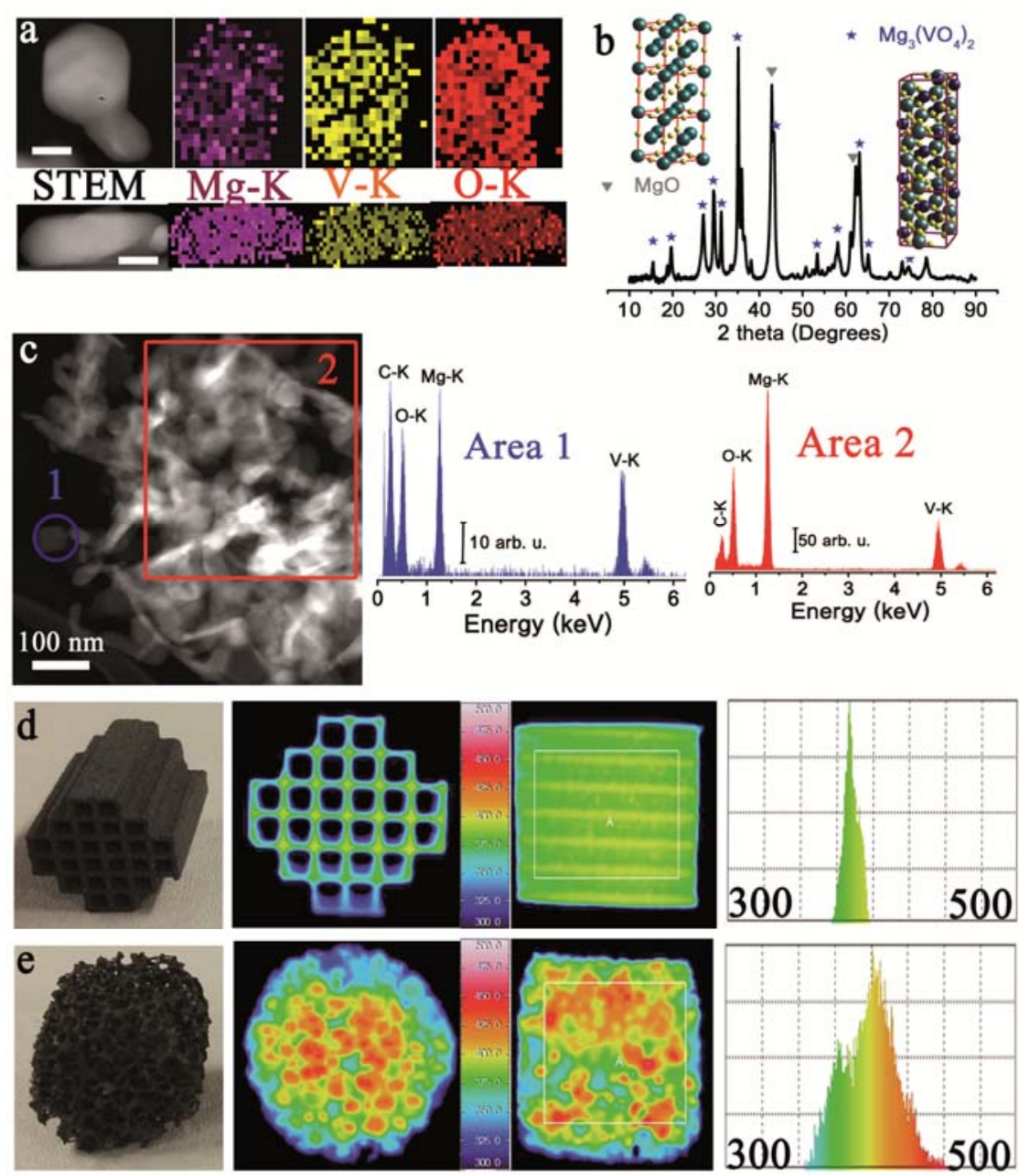

Figure 1. Characterization of the structured catalyst VMgO@SiC: a) Combined HAADF-STEM-EDX mapping analysis of two representative freestanding $\mathrm{VMgO}$ nanoparticles revealing a pseudo-planar structure with a 
homogeneous distribution of $\mathrm{Mg}, \mathrm{V}$ and $\mathrm{O}$ as demonstrated by EDX mapping. ( $\mathrm{V}=$ Purple, $\mathrm{O}=\mathrm{Red}, \mathrm{Mg}=$ Yellow; scale bar referred to $20 \mathrm{~nm}$ )); b) XRD spectrum of the $\mathrm{VMgO}$ catalyst including the presence of the $\mathrm{Mg}_{3}\left(\mathrm{VO}_{4}\right)_{2}$ phase and a secondary phase of MgO; c) HAADF-STEM imaging and corresponding EDX analysis of two different areas of the $\mathrm{VMgO}$ catalyst; The EDX corresponding to a broader area of catalyst (labeled as Area 2) exhibits a higher fraction of Mg in comparison with a single nanoparticle (labeled as Area 1); d) Digital micrograph of the $\mathrm{SiC}$ monolith and corresponding temperature mapping distribution of the microwave heated monolith including front and side views and temperature profiles acquired with the IR thermographic camera; e) Digital image and temperature mapping distribution of the microwave heated $\mathrm{SiC}$ foam including the front and side views and temperature profiles. Temperature histograms represent the temperature distribution of the boxes incorporated in the side view mappings. Power input $=40 \mathrm{~W}$. Temperature scale ranges from $300{ }^{\circ} \mathrm{C}$ to $500{ }^{\circ} \mathrm{C}$.

For this reason, the heating behavior of both silicon carbide supports under MW heating was initially evaluated in the absence of catalysts. The temperature profiles obtained with a thermal camera are shown in Figure 1d and Figure 1e. Significant differences on the temperature heating profiles of both $\mathrm{SiC}$ monolithic supports were observed. The temperature distribution on the monolith was more homogeneous than on the foam, having a temperature variation of only $\pm 12 \mathrm{~K}$ at an average temperature of $385^{\circ} \mathrm{C}$ (Figure 1d), while the foam-shaped SiC support showed the presence of multiple hot spots and wider temperature gradients of $\pm 54 \mathrm{~K}$ at $400{ }^{\circ} \mathrm{C}$ (Figure 1e). In addition, due to the more tortuous flow within the foam the gas-solid contact will be more intense [38], likely limiting the temperature gradient that could be established between the gas phase and the SiC support.

Finally, it was also observed that the foam reached higher temperatures than its monolith counterpart at equivalent power inputs (i.e. $40 \mathrm{~W}$ ) (Figure 1e). These differences can be attributed to the different structural composition of each support. XRD and Raman analysis confirmed that the ordered monolith was composed by hexagonal phases of $\alpha$-SiC (4H and $6 \mathrm{H}$ phases) (Figure $\mathrm{S} 4$ and Figure S5) while the foam contained $\beta$-SiC (cubic phase) and an additional fraction of carbonaceous nature according to the Raman bands detected at $1350 \mathrm{~cm}^{-1}$ and $1600 \mathrm{~cm}^{-1}$ (Figure S4 and Figure S5) [39]. The dielectric properties, in particular the electric loss tangent $\tan \delta=\varepsilon " / \varepsilon^{\prime}$ is higher for $\beta$-SiC $(\tan \delta=0.5)$ than for $\alpha-\operatorname{SiC}(\tan \delta=0.05)$ at temperatures between $500-600{ }^{\circ} \mathrm{C}$ [40]. This loss tangent value correlates the real and imaginary components of the permittivity $\left(\varepsilon=\varepsilon^{\prime}-\mathrm{j} \varepsilon^{\prime \prime}\right)$, that is the dielectric constant $\left(\varepsilon^{\prime}\right)$ and the dielectric loss factor $\left(\varepsilon^{\prime \prime}\right)$ and it is indicative of the capability of materials to 
convert microwave energy into thermal energy. In addition, the residual carbon content of $\beta$-SiC also contributes to the overall MW heating of the foam. As a result, the more intense MW heating by the $\beta$ $\mathrm{SiC}$ foam phase [40], together with its convoluted nature [41] and the presence of residual carbon, favor the formation of the hot spots as shown in Figure 1e.

To verify the possibility of establishing a stable solid-gas temperature gradient during reactor operation under MW heating, preliminary experiments were carried out using different heating systems while simultaneously measuring the temperature of the gas (using an optical fiber located $1 \mathrm{~mm}$ downstream from the monolith) and of the solid using a pyrometer that gives a reading of the top (exit) monolith surface (see Experimental Section). The results are shown in Figure 2, where it can be observed that a significant solid-gas temperature difference can be established when MW heating is used, while the gas and solid are at essentially the same temperature under conventional heating. Although the temperature limits of the optical fiber restrict the comparison to a maximum temperature of $300{ }^{\circ} \mathrm{C}$, extrapolation of the readings to the temperatures of propane oxidative dehydrogenation would give temperature differences around $40^{\circ} \mathrm{C}$.

These data are in line with those reported in our previous works [30, 31]. Additionally, the temperature gradient measured within the foam reactor is smaller than in the monolith due to the higher gas-solid contact, suggesting that these foams configurations will exhibit a less promising performance than the straight channeled monoliths. Therefore, in view of the more homogeneous heating achieved, the straight channel $\mathrm{SiC}$ monolith was selected for most of the reaction experiments described below. The VMgO catalyst was deployed by impregnation, forming deposits on the surface of the structured support and inside its macropores (see catalyst deposition in experimental section). Both structured supports were characterized by SEM coupled with EDX mapping analysis to confirm the homogeneous distribution of the $\mathrm{VMgO}$ active catalytic phase (Figure S6). 


\subsection{Evaluation of the propane $\mathrm{ODH}$ product distribution under $M W$ and conventional heating conditions}

As already mentioned, the propane $\mathrm{ODH}$ reaction may occur via two different pathways (see Scheme 1) that are temperature dependent. At temperatures below $550{ }^{\circ} \mathrm{C}$ reactions on the catalyst prevail, and oxidative dehydrogenation takes place following a purely heterogeneous Mars Van Krevelen mechanism [26]. Interestingly, the propylene selectivity, for a given conversion, increases with temperature since the apparent activation energy towards the propylene combustion is lower than that for dehydrogenation [24]. However, at temperatures above $550{ }^{\circ} \mathrm{C}$ gas-phase homogeneous contributions become increasingly dominant and eventually responsible for the product distribution observed [9, 23]. These homogeneous gas phase reactions follow two main routes: (i) the oxypyrolysis of propane [27], and (ii) the gas phase reactions with propyl radicals that are generated on the catalyst that, upon desorption from the catalyst surface, can react homogeneously with up to 70 propane molecules per radical $[42,43]$. In our study MW heating was used to enable operation with a stable solid-gas temperature difference with the ultimate goal of minimizing the undesired homogeneous contributions. Thus, the $\mathrm{SiC}$ monolith used as catalyst support underwent a rapid and selective heating under microwaves, while the gas phase remained at a lower temperature (see Figure 2).

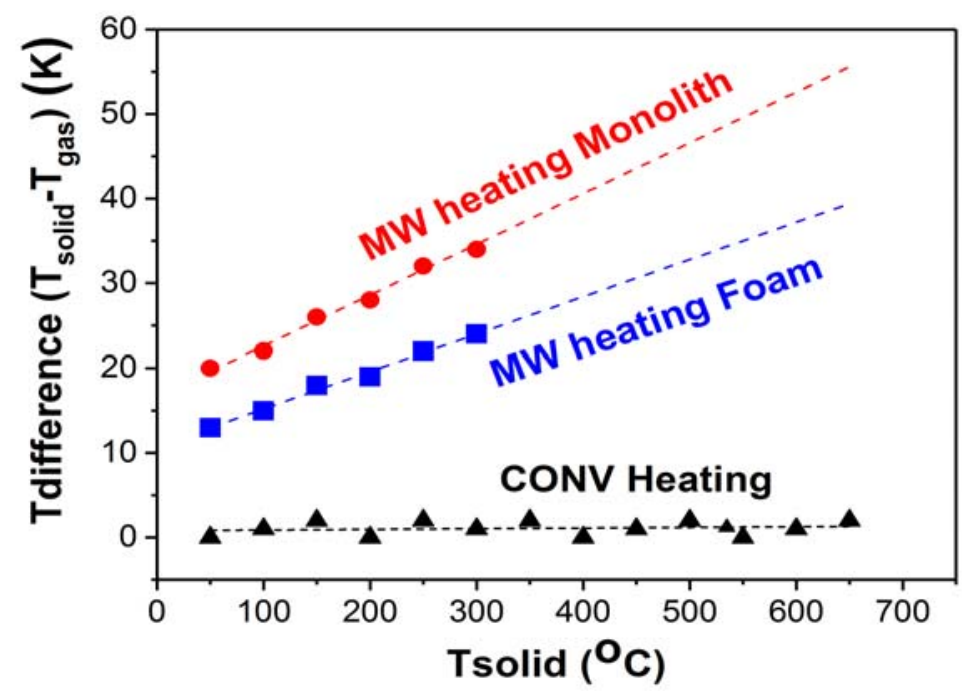

Figure 2. Determination of gas-solid temperature gaps: Gas-solid temperature gap for different solid phase temperatures under conventional and MW heating. 
A first set of blank experiments was carried out with naked (i.e. catalyst free) SiC supports either on a conventional furnace or inside the MW cavity. As expected, in a conventional furnace (where the catalyst and the gas phase are at essentially the same temperature [31]) the contribution of homogeneous reactions is significant, especially at temperatures higher than $550^{\circ} \mathrm{C}$. It can be observed (Figure $3 \mathrm{a}$ ) that at these temperatures, propane oxypyrolysis takes place and a wide distribution of gaseous products, including methane, propane, ethylene, propylene and carbon dioxide could be detected. In contrast (Figure 3b), when the same quartz reactor containing the monolith was heated inside the MW cavity, selective heating of the $\mathrm{SiC}$ support takes place and, at the same solid temperature, no secondary homogeneous gas phase reactions take place as consequence of the colder gas phase. The detailed product concentrations can be found in Table S1 and Table S2.
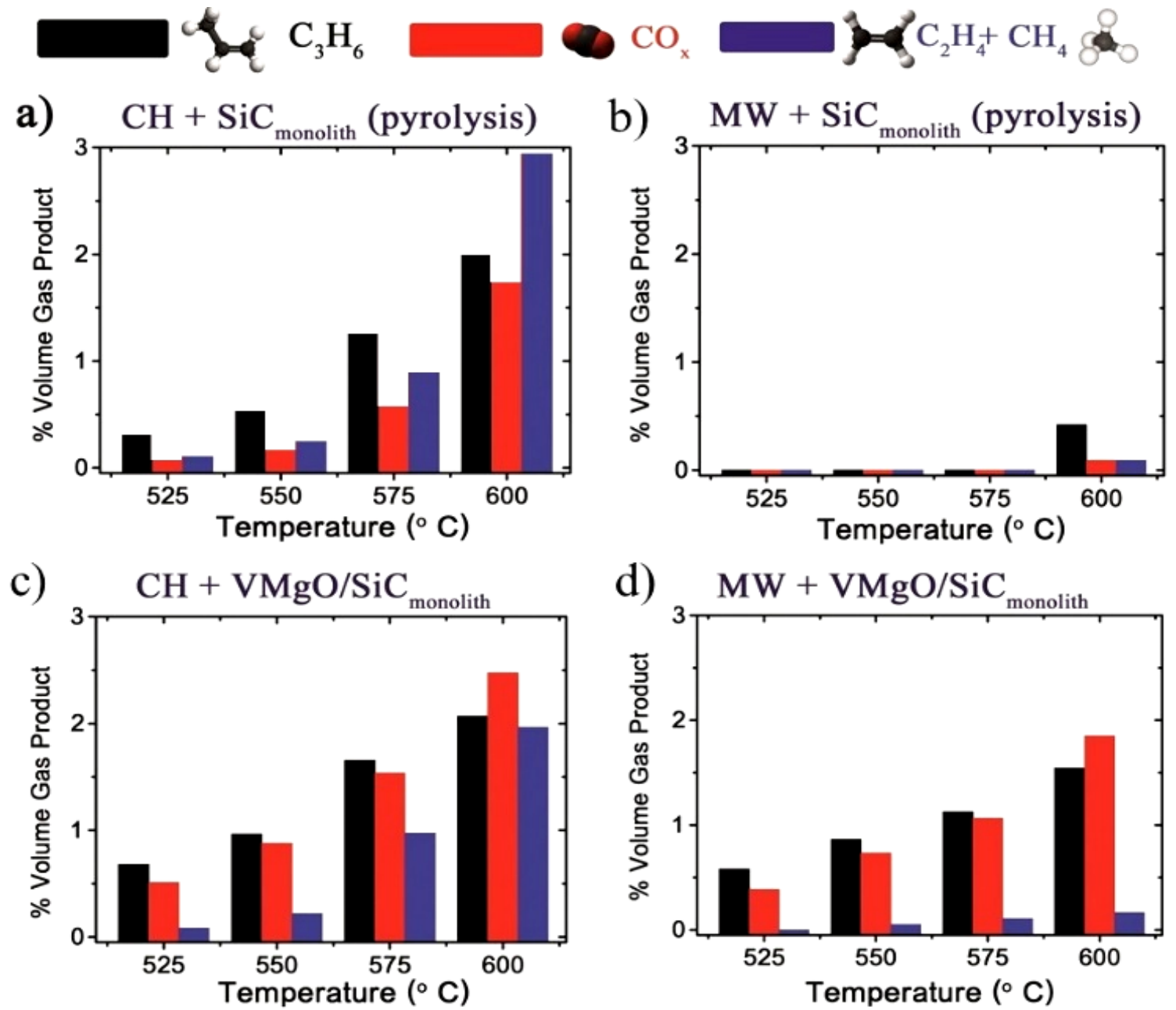

Figure 3. Product distribution after the propane ODH reaction under different reaction conditions: a) Product distribution of the $\mathrm{SiC}$ monolith support at different reaction temperatures with conventional $(\mathrm{CH})$ heating; b) 
Product distribution of the $\mathrm{SiC}$ monolith support at different reaction temperatures with microwave (MW) heating; c) Product distribution of the VMgO-SiC monolith support at different reaction temperatures with conventional $(\mathrm{CH})$ heating; d) Product distribution of the VMgO-SiC monolith support at different reaction temperatures with microwave (MW) heating. $\mathrm{Q}=100 \mathrm{~mL} / \mathrm{min}$. Reaction mixture: $10 \%$ Propane, $5 \%$ Oxygen, $85 \%$ Helium.

The product distributions for the loaded monolith (i.e. SiC monolith plus $\mathrm{V} / \mathrm{MgO}$ catalyst) under conventional and microwave heating, are displayed in Figures $3 \mathrm{c}$ and $3 \mathrm{~d}$ respectively. A significant difference between the product distributions obtained by both heating mechanisms can be easily observed. The formation of secondary by-products such as ethylene and methane was considerably minimized under MW heating conditions (up to $80 \%$ lower at $600{ }^{\circ} \mathrm{C}$ ). This reduction is attributed to the lower temperature of the gas phase and the corresponding decrease of the homogeneous pathways. Likewise, this large reduction of the ethylene and methane formation translated into a strong increase of the selectivity to propylene under MWH conditions (see Figure 4a). 

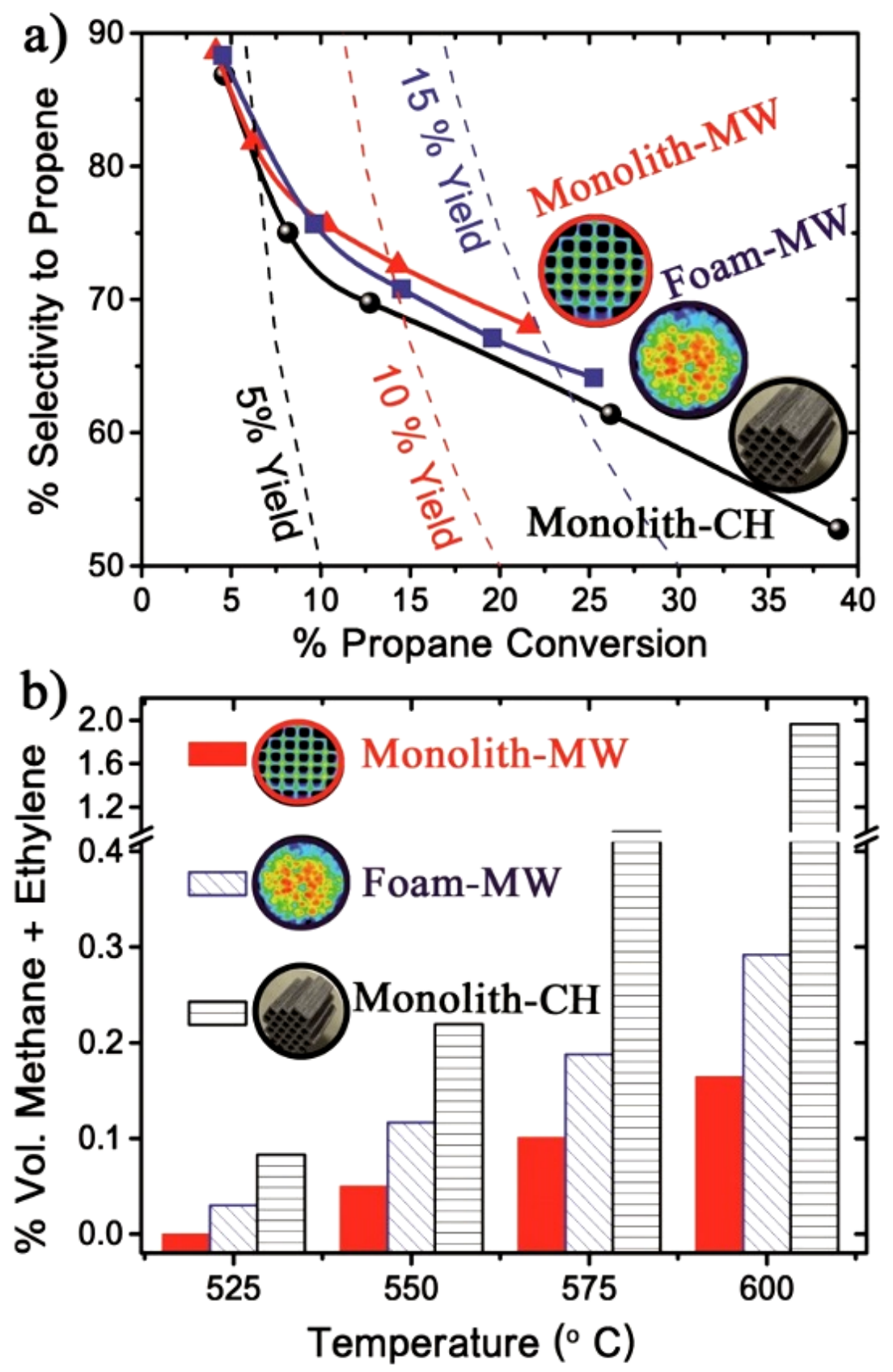

Figure 4. Evaluation of the selectivity to products in the propane ODH: a) Selectivity of propylene versus conversion for the $\mathrm{VMgO}-\mathrm{SiC}$ monolith and foam supports under microwave and conventional heating. Dash lines represent isoyield values; b) Ethylene and methane formation at different temperatures for the $\mathrm{VMgO}-\mathrm{SiC}$ monolith and foam supports under microwave and monolith conventional heating. $\mathrm{Q}=100 \mathrm{~mL} / \mathrm{min}$. Reaction mixture: $10 \%$ Propane, $5 \%$ Oxygen, $85 \%$ Helium.

As a comparison, the performance of the $\mathrm{SiC}$ foam support was also evaluated and the catalytic outcome was consistent with our previous assumptions: the more intense heat exchange in the foam due to the tortuous path of the gas means that the gas-solid temperature gap is less significant. As a 
consequence the selectivity to propylene, though better than under $\mathrm{CH}$ conditions, is lower than for the straight channel $\mathrm{SiC}$ monolith. Indeed, Figure $4 \mathrm{~b}$ shows that the formation of ethylene and methane, undesired gas phase products, was more favored in the foam structured support indicating a higher average gas temperature compared to the straight channel monolith. To confirm that these differences were not caused by the different $\mathrm{SiC}$ crystalline phase $(\beta-\mathrm{SiC} / \alpha-\mathrm{SiC})$ or due to interactions catalystsupport, we tested both structured reactors under conventional heating (see Figure S7). We observed an analogous performance for both supports under conventional heating, thereby discarding the influence of the $\mathrm{SiC}$ structured materials on the $\mathrm{VMgO}$ catalyst performance under $\mathrm{CH}$ conditions.

Finally, it is worth mentioning that the production rate of propylene achieved in the straight monolith under $\mathrm{MW}$ heating using a standard $\mathrm{V} / \mathrm{MgO}$ catalyst reached $3.4 \mathrm{kgC}_{3} \mathrm{H}_{6} / \mathrm{kgcat} \cdot \mathrm{h}$, above typical values of the literature [10, 17, 44, 45], including state of the art catalysts (see Figure 5) and not too far from the $3.8 \mathrm{kgC}_{3} \mathrm{H}_{6} / \mathrm{kgcat} \cdot \mathrm{h}$ recently reported for a sophisticated boron nitride nanotubes catalyst [10]. These values are considered close to those required for commercial implementation [8]. It is clear that, for a given temperature, the intrinsic performance of the $\mathrm{VMgO}$ catalyst used is far from that of those made from boron nitride nanotubes. The fact that comparable productivities are obtained is simply due to the fact that MW heating allows operating with a lower gas phase temperature, and therefore the solid temperature can be increased to higher values than other catalysts performing under conventional heating. Furthermore, thanks to the temperature gradient, the selectivity to propylene reported in this work is the highest among vanadium-based catalyst (see Figure 5b), with more than 30 points of difference for similar reported yields [46]. 
a)

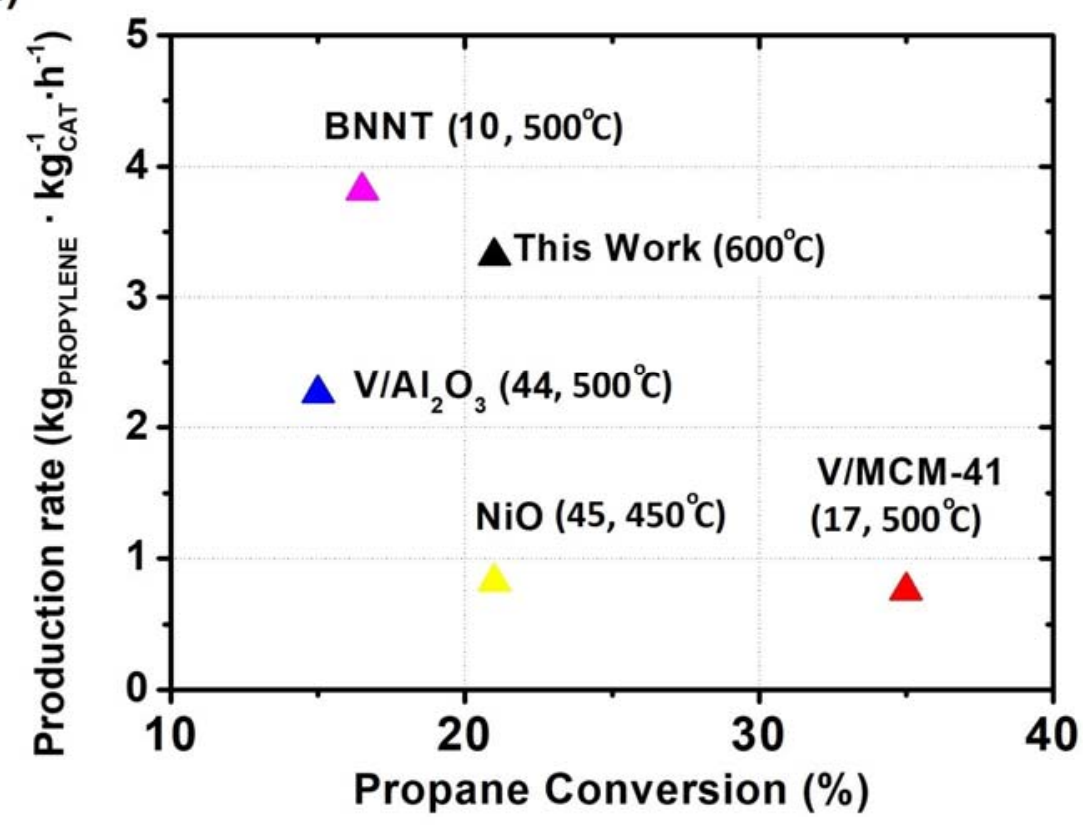

b)

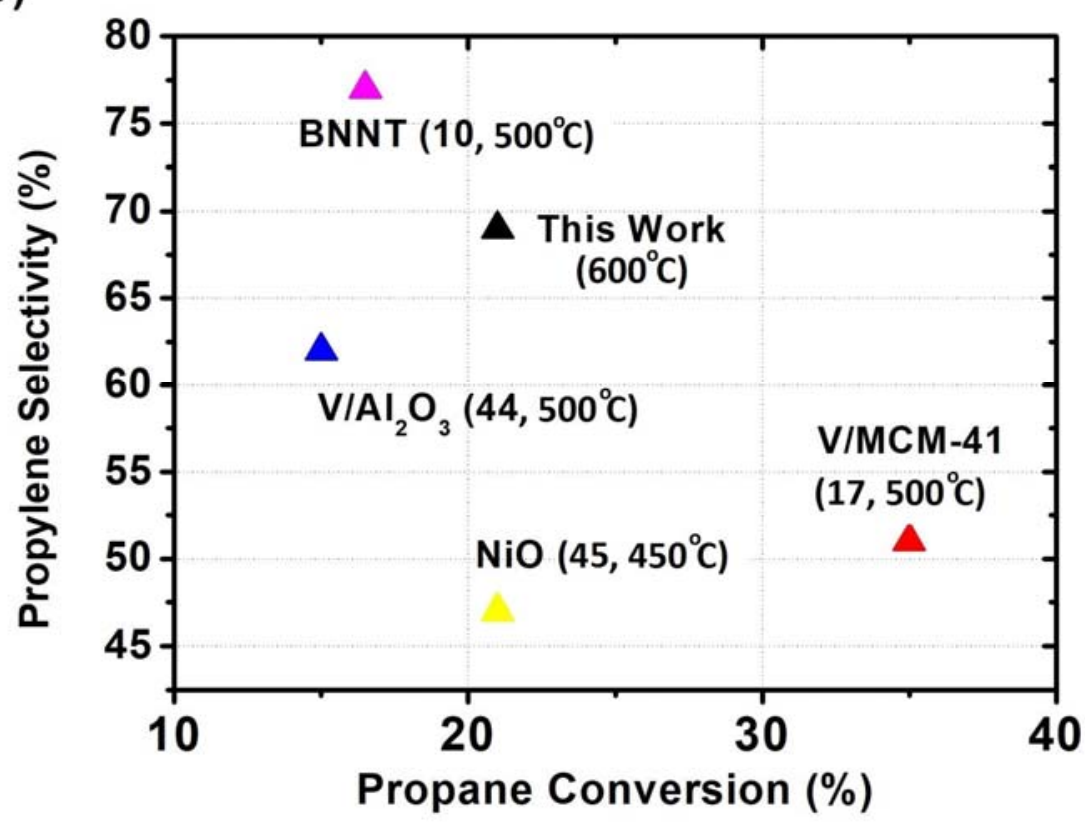

Figure 5. Comparison of the propylene productivity of the $\mathrm{VMgO}-\mathrm{SiC}$ monolith under $\mathrm{MW}$ irradiation and some of the best catalysts reported in the literature for propane conversion values higher than $10 \%$. Values in parenthesis represent the reference and temperature of each point.

\section{Conclusions}

Although MW absorption by a standard $\mathrm{VMgO}$ catalyst is low, microwave heating can be successfully applied for the oxidative dehydrogenation of propane when the catalyst is deposited on a good microwave susceptor, such as a SiC structured monolith. Thanks to the preferential solid heating 
afforded by microwaves, a significant solid-gas temperature gap is induced. This cooler gas phase prevents the homogeneous formation of ethylene and methane that takes place intensely at gas phase temperatures above $550^{\circ} \mathrm{C}$. As a consequence, higher selectivity to propylene is achieved in comparison with conventional heating conditions. The $\mathrm{SiC}$ monolith with straight channels performs better than the foam-like monolith due to the less intense heat transfer in the straight channel monolith that translates into a higher solid-gas temperature gradient. The lower gas phase temperature leads to a consistent increase of selectivity around 5 percentage points throughout a wide conversion interval when compared to conventional heating (see Figure 4). In addition, the catalyst temperature can be increased while still maintaining a gas phase temperature within acceptable values, and therefore the productivity obtained approaches that obtained with much more efficient catalysts. The results shown here for propane oxidative dehydrogenation under MW heating are, in principle, applicable to any catalytic system with undesired contributions in the gas phase, allowing to increase the selectivity towards the products of interest by minimizing these homogeneous contributions.

\section{Acknowledgements}

Financial support from the European Research Council Advanced Grant (HECTOR-267626) and the Regional Government of Aragon (DGA) is gratefully acknowledged. The CIBER-BBN (initiative funded by the VI National R\&D\&i Plan 2008-2011, Iniciativa Ingenio 2010, Consolider Program, CIBER Actions and financed by the Instituto de Salud Carlos III with assistance from the European Regional Development Fund) is gratefully acknowledged. The synthesis of materials has been performed by the Platform of Production of Biomaterials and Nanoparticles of the NANOBIOSIS ICTS, more specifically by the Nanoparticle Synthesis Unit of the CIBER in BioEngineering, Biomaterials \& Nanomedicine (CIBER-BBN). 


\section{References}

[1] H.H. Kung, Oxidative Dehydrogenation of Light (C2 to C4) Alkanes, in: D.D. Eley, H. Pines, W.O. Haag (Eds.) Advances in Catalysis, Academic Press 1994, pp. 1-38.

[2] T. Blasco, J.M.L. Nieto, Oxidative dehydrogenation of short chain alkanes on supported vanadium oxide catalysts, Appl Catal a-Gen 157 (1997) 117-142.

[3] B. Thinnes, 'On-purpose' propylene production, Hydrocarb Process 89 (2010) 19-19.

[4] A.M. Aitani, Advances in propylene production routes, Oil Gas-Eur Mag 30 (2004) 36-39.

[5] D. Akporiaye, S.F. Jensen, U. Olsbye, F. Rohr, E. Rytter, M. Ronnekleiv, A.I. Spjelkavik, A novel, highly efficient catalyst for propane dehydrogenation, Ind Eng Chem Res 40 (2001) 4741-4748.

[6] F.E. Frey, W.F. Huppke, Equilibrium dehydrogenation of ethane, propane, and the Butanes, Ind Eng Chem 25 (1933) 54-59.

[7] F. Cavani, F. Trifiro, The Oxidative Dehydrogenation of Ethane and Propane as an Alternative Way for the Production of Light Olefins, Catal Today 24 (1995) 307-313.

[8] F. Cavani, N. Ballarini, A. Cericola, Oxidative dehydrogenation of ethane and propane: How far from commercial implementation?, Catal Today 127 (2007) 113-131.

[9] R. Burch, E.M. Crabb, Homogeneous and Heterogeneous Contributions to the Oxidative Dehydrogenation of Propane on Oxide Catalysts, Appl Catal a-Gen 100 (1993) 111-130.

[10] J.T. Grant, C.A. Carrero, F. Goeltl, J. Venegas, P. Mueller, S.P. Burt, S.E. Specht, W.P. McDermott, A. Chieregato, I. Hermans, Selective oxidative dehydrogenation of propane to propene using boron nitride catalysts, Science 354 (2016) 1570-1573.

[11] V. Niemi, Process for the Dehydrogenation of alkanes and a catalyst for use therein, EP0790225A1 (1996).

[12] N.S.C. Ltd, Vanadium-containing catalysts, process for manufacturing and use of the same, CN104230624B (2013).

[13] K.F.U.o.P.a. Minerals, Fluidizable vanadium catalyst for oxidative dehydrogenation of alkanes to olefins in a gas phase oxygen free environment, US9878305B2 (2016). 
[14] A. Burrows, C.J. Kiely, J. Perregaard, P.E. Hojlund-Nielsen, G. Vorbeck, J.J. Calvino, C. LopezCartes, Structural characterisation of a $\mathrm{VMgO}$ catalyst used in the oxidative dehydrogenation of propane, Catal Lett 57 (1999) 121-128.

[15] D. Creaser, B. Andersson, Oxidative dehydrogenation of propane over V-Mg-O: Kinetic investigation by nonlinear regression analysis, Appl Catal a-Gen 141 (1996) 131-152.

[16] R. Ramos, M.P. Pina, M. Menendez, J. Santamaria, G.S. Patience, Oxidative dehydrogenation of propane to propene, 1: Kinetic study on V/MgO, Can J Chem Eng 79 (2001) 891-901.

[17] B. Frank, A. Dinse, O. Ovsitser, E.V. Kondratenko, R. Schomacker, Mass and heat transfer effects on the oxidative dehydrogenation of propane (ODP) over a low loaded VOx/A12O3 catalyst, Appl Catal a-Gen 323 (2007) 66-76.

[18] O. Schwarz, D. Habel, O. Ovsitser, E.V. Kondratenko, C. Hess, R. Schomacker, H. Schubert, Impact of preparation method on physico-chemical and catalytic properties of VOx/gamma-A12O3 materials, J Mol Catal a-Chem 293 (2008) 45-52.

[19] G. Martra, F. Arena, S. Coluccia, F. Frusteri, A. Parmaliana, Factors controlling the selectivity of V2O5 supported catalysts in the oxidative dehydrogenation of propane, Catal Today 63 (2000) 197-207. [20] S.A. Karakoulia, K.S. Triantafyllidis, G. Tsilomelekis, S. Boghosian, A.A. Lemonidou, Propane oxidative dehydrogenation over vanadia catalysts supported on mesoporous silicas with varying pore structure and size, Catal Today 141 (2009) 245-253.

[21] A. Dinse, S. Khennache, B. Frank, C. Hess, R. Herbert, S. Wrabetz, R. Schlogl, R. Schomacker, Oxidative dehydrogenation of propane on silica (SBA-15) supported vanadia catalysts: A kinetic investigation, J Mol Catal a-Chem 307 (2009) 43-50.

[22] E.V. Kondratenko, M. Cherian, M. Baerns, D.S. Su, R. Schlogl, X. Wang, I.E. Wachs, Oxidative dehydrogenation of propane over V/MCM-41 catalysts: comparison of O-2 and N2O as oxidants, J Catal 234 (2005) 131-142.

[23] K.T. Nguyen, H.H. Kung, Generation of Gaseous Radicals by a V-Mg-O Catalyst during Oxidative Dehydrogenation of Propane, J Catal 122 (1990) 415-428. 
[24] C.A. Carrero, R. Schloegl, I.E. Wachs, R. Schomaecker, Critical Literature Review of the Kinetics for the Oxidative Dehydrogenation of Propane over Well-Defined Supported Vanadium Oxide Catalysts, Acs Catal 4 (2014) 3357-3380.

[25] D. Shee, T.V.M. Rao, G. Deo, Kinetic parameter estimation for supported vanadium oxide catalysts for propane ODH reaction: Effect of loading and support, Catal Today 118 (2006) 288-297.

[26] M.Y. Sinev, Free radicals in catalytic oxidation of light alkanes: kinetic and thermochemical aspects, J Catal 216 (2003) 468-476.

[27] V.S. Arutyunov, R.N. Magomedov, Gas-phase oxypyrolysis of light alkanes, Russ Chem Rev +81 (2012) 790-822.

[28] V.A. Sadykov, S.N. Pavlova, N.F. Saputina, I.A. Zolotarskii, N.A. Pakhomov, E.M. Moroz, V.A. Kuzmin, A.V. Kalinkin, Oxidative dehydrogenation of propane over monoliths at short contact times, Catal Today 61 (2000) 93-99.

[29] S.N. Pavlova, V.A. Sadykov, Y.V. Frolova, N.F. Saputina, P.M. Vedenikin, I.A. Zolotarskii, V.A. Kuzmin, The effect of the catalytic layer design on oxidative dehydrogenation of propane over monoliths at short contact times, Chem Eng J 91 (2003) 227-234.

[30] A. Ramirez, J.L. Hueso, R. Mallada, J. Santamaria, In situ temperature measurements in microwave-heated gas-solid catalytic systems. Detection of hot spots and solid-fluid temperature gradients in the ethylene epoxidation reaction, Chem Eng J 316 (2017) 50-60.

[31] A. Ramirez, J.L. Hueso, M. Abian, M.U. Alzueta, R. Mallada, J. Santamaria, Escaping undesired gas-phase chemistry: Microwave-driven selectivity enhancement in heterogeneous catalytic reactors, Sci Adv 5 (2019).

[32] J.Y. Chen, W.H. Hsu, C.L. Huang, Dielectric properties of magnesium oxide at microwave frequency, J Alloy Compd 504 (2010) 284-287.

[33] H.H. Kung, M.C. Kung, Oxidative dehydrogenation of alkanes over vanadium-magnesium-oxides, Appl Catal a-Gen 157 (1997) 105-116. 
[34] M.A. Chaar, D. Patel, H.H. Kung, Selective Oxidative Dehydrogenation of Propane over V-Mg-O Catalysts, J Catal 109 (1988) 463-467.

[35] A. Ramirez, J.L. Hueso, R. Mallada, J. Santamaria, Ethylene epoxidation in microwave heated structured reactors, Catal Today 273 (2016) 99-105.

[36] H.J. Yang, J. Yuan, Y. Li, Z.L. Hou, H.B. Jin, X.Y. Fang, M.S. Cao, Silicon carbide powders: Temperature-dependent dielectric properties and enhanced microwave absorption at gigahertz range, Solid State Commun 163 (2013) 1-6.

[37] S. Horikoshi, M. Kamata, T. Mitani, N. Serpone, Control of Microwave-Generated Hot Spots. 6. Generation of Hot Spots in Dispersed Catalyst Particulates and Factors That Affect Catalyzed Organic Syntheses in Heterogeneous Media, Ind Eng Chem Res 53 (2014) 14941-14947.

[38] F.C. Patcas, G.I. Garrido, B. Kraushaar-Czarnetzki, CO oxidation over structured carriers: A comparison of ceramic foams, honeycombs and beads, Chem Eng Sci 62 (2007) 3984-3990.

[39] S. Nakashima, H. Harima, Raman investigation of SiC polytypes, Phys Status Solidi A 162 (1997) $39-64$.

[40] K.S. Leiser, D.E. Clark, Effects of silicon carbide structure on the microwave properties of silicon carbide alumina cement susceptors, Ceram Eng Sci Proc 19 (1998) 367-372.

[41] L. Fratalocchi, C. Giorgio, V.G. Groppi, L. Lietti, E. Tronconi, Intensifying heat transfer in Fischer-Tropsch tubular reactors through the adoption of conductive packed foams, Chem Eng J 349 (2018) 829-837.

[42] L. Leveles, K. Seshan, J.A. Lercher, L. Lefferts, Oxidative conversion of propane over lithiumpromoted magnesia catalyst - I. Kinetics and mechanism, J Catal 218 (2003) 296-306.

[43] L. Leveles, K. Seshan, J.A. Lercher, L. Lefferts, Oxidative conversion of propane over lithiumpromoted magnesia catalyst - II. Active site characterization and hydrocarbon activation, J Catal 218 (2003) 307-314. 
[44] C. Carrero, M. Kauer, A. Dinse, T. Wolfram, N. Hamilton, A. Trunschke, R. Schlogl, R. Schomacker, High performance $(\mathrm{VOx})(\mathrm{n})-(\mathrm{TiOx})(\mathrm{m}) / \mathrm{SBA}-15$ catalysts for the oxidative dehydrogenation of propane, Catal Sci Technol 4 (2014) 786-794.

[45] J.H. Li, C.C. Wang, C.J. Huang, Y.F. Sun, W.Z. Weng, H.L. Wan, Mesoporous nickel oxides as effective catalysts for oxidative dehydrogenation of propane to propene, Appl Catal a-Gen 382 (2010) 99-105.

[46] M. Hoj, A.D. Jensen, J.D. Grunwaldt, Structure of alumina supported vanadia catalysts for oxidative dehydrogenation of propane prepared by flame spray pyrolysis, Appl Catal a-Gen 451 (2013) 207-215. 